CLINICAL STUDY

\title{
Midnight serum cortisol as a marker of increased cardiovascular risk in patients with a clinically inapparent adrenal adenoma
}

Massimo Terzolo, Silvia Bovio, Anna Pia ${ }^{1}$, Pier Antonio Conton ${ }^{4}$, Giuseppe Reimondo, Chiara Dall'Asta ${ }^{2}$, Donatella Bemporad ${ }^{3}$, Alberto Angeli, Giuseppe Opocher ${ }^{4}$, Massimo Mannelli ${ }^{3}$, Bruno Ambrosi ${ }^{2}$ and Franco Mantero ${ }^{4}$

Dipartimento di Scienze Cliniche e Biologiche, Medicina Interna I, Università di Torino, Turin, Orbassano, Italy ${ }^{1}$ Unità Operativa di Endocrinologia, Azienda Sanitaria Ospedaliera S. Croce e Carle, Cuneo, Italy ${ }^{2}$ Dipartimento di Scienze Mediche e Chirurgiche, U.O. di Endocrinologia, Università di Milano, Milan, Italy ${ }^{3}$ Dipartimento di Fisiopatologia Clinica, U.O. di Endocrinologia, Università di Firenze, Florence, Italy and ${ }^{4}$ Dipartimento di Scienze Cliniche e Chirurgiche, Divisione di Endocrinologia, Università di Padova, Padua, Italy

(Correspondence should be addressed to M Terzolo, Medicina Interna I, A.S.O. San Luigi, Regione Gonzole, 10, 10043 Orbassano, Italy; Email: terzolo@usa.net

\begin{abstract}
Objective: There is scant information on the morbidity associated with subclinical Cushing's syndrome in patients with a clinically inapparent adrenal adenoma. In the present study, we have determined the prevalence of alterations of the hypothalamic-pituitary-adrenal axis in such patients and examined whether any correlation between endocrine data and the clinical phenotype exists.

Design and methods: A multi-institutional retrospective study was carried out on 210 patients (135 women and 75 men aged 19-81 years) with an adrenal adenoma detected serendipitously between 1996 and 2000 in four referral centers in Italy.

Results: Hypertension was observed in $53.8 \%$, obesity in $21.4 \%$ and hyperglycemia in $22.4 \%$ of patients. The 47 patients with midnight serum cortisol $>5.4 \mu \mathrm{g} / \mathrm{dl}$, a value corresponding to the 97th centile of 100 controls, were older and displayed greater fasting glucose $(120.4 \pm 52.2 \mathrm{mg} / \mathrm{dl}$ vs $105.1 \pm 39.2 \mathrm{mg} / \mathrm{dl}, \quad P=0.04)$ and systolic blood pressure $(148.3 \pm 14.6 \mathrm{mmHg}$ vs $136.4 \pm 16.2 \mathrm{mmHg}, P=0.0009)$ than the 113 patients with normal cortisol levels. The difference in systolic blood pressure remained statistically significant $(P=0.009)$ when age was used as a covariate. The percentage of hypertensive patients undergoing treatment was not different between the two groups (90.5 and $97.1 \%$ ) but the percentage of patients with controlled hypertension was significantly lower among the hypercortisolemic patients ( $12.5 \mathrm{vs} 32.4 \%, P=0.04)$. Glycated haemoglobin $(\mathrm{HbA} 1 \mathrm{c})$ levels were higher in the hypercortisolemic diabetic patients $(8.9 \pm 1.1 \%$ vs $7.1 \pm 1.3 \%, P=0.005)$. Conclusions: Elevated midnight cortisol concentration is a reliable test to select a subgroup of patients with a clinically inapparent adrenal adenoma with an adverse cardiovascular risk profile.
\end{abstract}

European Journal of Endocrinology 153 307-315

\section{Introduction}

Clinically inapparent adrenal masses are discovered serendipitously, in the course of diagnostic testing or treatment for unrelated disorders, and thus are commonly known as adrenal incidentalomas (1-3). Improvement in imaging techniques has resulted in the detection of an increasing number of adrenal incidentalomas; thus they are currently being found (serendipitously) in millions of people worldwide (3). Because the incidence of these tumors increases with age $(4,5)$, appropriate management of adrenal incidentalomas will be a growing public health challenge for our aging society $(2,3)$.
Management algorithms and current practice vary widely across different centers $(1-3,6-11)$. The first problem is that adrenal incidentaloma is not a single disease entity but rather a heterogeneous spectrum of different pathologies $(1-3,9)$. An adrenal incidentaloma that is found to be a primary or secondary malignancy, or pheochromocytoma as well, can significantly affect patients' health. However, the potential harm to health associated with incidentally discovered cortical adenoma, the most frequent tumor among adrenal incidentalomas, is presently unclear $(2,3,10-12)$.

Incidentally discovered adrenal adenomas may secrete cortisol autonomously, in a way that is no 
longer under close control by pituitary feedback, in $5-20 \%$ of cases, depending on variable study protocols and diagnostic criteria used across different series (9-13). This particular endocrine disorder, which has been called subclinical Cushing's syndrome (14) or subclinical autonomous glucocorticoid hypersecretion (2), is difficult to characterize because there is a continuum from normality to autonomy and the degree of cortisol excess may only slightly exceed the physiological daily production rate of cortisol $(2,13)$. As a consequence, a number of different alterations in the endocrine tests aimed at assessing the function of the hypothalamic-pituitary-adrenal (HPA) axis may be found (14-17). Moreover, this heterogeneous condition cannot be well defined on clinical grounds because such patients do not present with a specific phenotype. Notwithstanding the uncertainty regarding the ascertainment of subclinical Cushing's syndrome, there is no doubt that many patients with a clinically inapparent adrenal adenoma can be exposed to chronic, subtle cortisol excess. Thus, it is biologically plausible to assume that they may suffer, at least to some extent, from the detrimental effects of sustained cortisol excess. The demonstration of end organ complications of this 'biochemical' diagnosis would add strength to the concept of cortisol excess in these patients. Complementary results from different studies support the view that the patients with subclinical Cushing's syndrome may represent a population at increased risk for metabolic disorders and cardiovascular complications (18). In this context, we have recently demonstrated that the slight hypercortisolism observed in some patients with clinically inapparent adrenal adenoma may contribute to the development of the phenotype of insulin resistance (19).

In the present study, data from the Italian Adrenal Incidentaloma Database were used to determine the prevalence of alterations of the HPA axis in patients with a clinically inapparent adrenal adenoma and to examine whether any correlation between endocrine data and the clinical phenotype of such patients does exist.

\section{Patients and methods}

\section{Patients}

The Italian Adrenal Incidentaloma Database contains demographic and clinical details of 210 patients with an adrenal adenoma detected serendipitously between 1 January 1996 and 31 December 2000 in four referral centers in Italy (Turin, Milan, Padua and Florence). Since 1995, each center has adopted the same definition of adrenal incidentaloma and a similar radiological and biochemical work-up. The recruitment pattern of these centers was similar, including patients referred by general practitioners, radiologists and other medical or surgical specialists, as well as patients in whom the diagnosis was first made in the center. According to the definition of adrenal incidentaloma (i.e. an adrenal mass detected serendipitously by an imaging workup performed for the evaluation of unrelated diseases in patients without clear signs or symptoms suggestive of adrenal disease), exclusion criteria a priori were severe or paroxysmal arterial hypertension, hypokalemia $(<3.5 \mathrm{mEq} / \mathrm{l})$ and clinical signs of hypercortisolism or hyperandrogenism (9). In the hypertensive patients included in the study, an abdominal imaging study was requested for some complaint that did not relate to the study of hypertension. In addition, patients with previous or current history of malignancies known to metastasize commonly in the adrenal glands, such as lung, breast and kidney cancers and melanoma, were considered non-eligible. Details concerning patients were obtained retrospectively from their medical records by means of a specifically tailored data form. A detailed explanation of all items of the data form was given. All of the data forms were individually checked for inconsistencies before statistical analysis. Double inclusion of the same patient was checked and avoided.

From the overall series of adrenal incidentalomas, only the patients with a cortical adenoma were selected for the study. When not histologically proven, the diagnosis of cortical adenoma rested on the following computed tomography (CT) criteria: size less than $6.0 \mathrm{~cm}$, regular shape with well-defined margins, and homogenous and hypodense content. An attenuation value of 10 or less Hounsfield units on unenhanced CT scan and 30 or less Hounsfield units on enhanced CT scan were considered to be suggestive of an adrenal adenoma. The diagnosis of adenoma was confirmed by a repeat CT scan after 3-6 months showing no significant increase in mass size, or change in mass density, in any patient $(1,2,9)$. Patient selection was also based on the results of an initial endocrine evaluation requiring normal 24-h urinary excretion of catecholamines and vanillyl mandelic acid to exclude silent pheochromocytoma and normal plasma aldosterone to plasma renin activity (PRA) ratio to exclude normokalemic hyperaldosteronism (2, 9-11).

During the study period, 210 patients with an adrenal mass of incidental detection met the inclusion criteria. They were 135 women and 75 men aged between 19 and 81 years (median 60 years). There were no major differences in the demographic characteristics of the patients across the different centers. Twenty-two patients in the present series were included in a previous report (19). The number of patients who were categorized as overweight, hypertensive, hyperglycemic, or who suffered from previous cardiovascular or cerebrovascular events was rated. Patients continued any previous medication because it was considered unethical to stop current treatment for hypertension, diabetes or dyslipidemia in order to study patients in a wash-out state. 
A consecutive series of 100 patients ( 78 women and 22 men aged between 18-81 years, median 44.6) with untreated microprolactinoma served as controls for the measurement of midnight serum cortisol concentration. The patients, who were enrolled at the different centers during the study period, had no clinical or biochemical sign of hypopituitarism. The patients were not suffering from depression nor were they taking any drug known to interfere with the HPA axis (20); prevalence rates of hypertension, diabetes and obesity were $37.9 \%, 5.2 \%$ and $21 \%$. The study was designed in agreement with the Declaration of Helsinki and was approved by the local Ethical Committees. The patients and controls volunteered for the study, gave their informed consent and were all hospitalized for the study.

\section{Methods}

During the time-span considered in this retrospective analysis, the patients with incidentally discovered adrenal adenoma underwent a specific diagnostic protocol. It included patient interview, physical examination, chest radiograph, 12-lead electrocardiogram, routine laboratory evaluation and an endocrine work-up aimed at studying the HPA axis. Plasma glucose levels were measured by standard enzymatic colorimetric tests (Hitachi 747 Instrument, God-Pap; Boehringer Mannheim, Meylan, France). Total serum cholesterol, high-density lipoprotein cholesterol and serum triglycerides were measured by routine clinical chemistry methods (Dry Chemistry Vitros, Ortho-Clinical Diagnostics, Inc. Indigo Creek Drive, Rochester, New York). Endocrine evaluation consisted of: (a) measurement of serum cortisol at 0800 and $1200 \mathrm{~h}$ (missing data $23.8 \%$ ), (b) measurement of serum dehydroepiandrosterone sulfate (DHEAS) at $0800 \mathrm{~h}$ (missing data $12.4 \%$ ), (c) measurement of the 24-h excretion of urinary free cortisol (UFC) (missing data 13.3\%), (d) measurement of plasma adrenocorticotropin (ACTH) at $0800 \mathrm{~h}$ (missing data 6.6\%), (e) overnight low-dose dexamethasone suppression test $(1 \mathrm{mg}$, orally, at $2300 \mathrm{~h}$ with measurement of serum cortisol at $0800 \mathrm{~h}$ the following morning) (missing data 20.5\%). Premenopausal women were studied in the early follicular phase of the menstrual cycle.

Hormones were measured in house at each participating center; determination of serum midnight cortisol in control subjects was performed at the Cuneo center. Serum and urinary cortisol and serum DHEAS were measured using commercially available RIAs (Sorin Biomedica, Saluggia, Italy; Radim Spa, Pomezia, Rome, Italy; Diagnostic Product Corporation, Los Angeles, CA, USA). Intra-assay and interassay coefficients of variation of these assays were $<6 \%$ and $<11.5 \%$ respectively. Plasma ACTH was measured by commercially available immunoradiometric assays (Nichols Institute, San Juan Capistrano, CA, USA; CIS Biointernational, Gif-sur-Yvette, France). Intra-assay coefficients of variation ranged from 2.1 to $5.3 \%$ and interassay coefficients of variation ranged from 3.1 to $8.9 \%$ respectively; sensitivity ranged from 2 to $5 \mathrm{pg} / \mathrm{ml}(0.44-1.1 \mathrm{pmol} / \mathrm{l})$. All samples for each subject were batched and run in duplicate in the same assay. There was a good correlation between the results of serum cortisol measurement obtained by the different laboratories in a set of samples at different concentrations, and reference ranges for morning serum cortisol were superimposable across the different centers. In contrast, the results of the measurement of ACTH, UFC and DHEAS differed somewhat across the centers, as did the reference ranges of these hormones. Therefore, ACTH, UFC and DHEAS concentrations were expressed and analyzed as percent values of the relevant limit of their respective age- and sex-adjusted reference ranges, as they were defined in each laboratory in large groups of healthy subjects. Thus, ACTH and DHEAS concentrations are expressed as percent of the lower limit of the normal range while UFC is expressed as percent of the upper limit. Adequate dexamethasone suppression was demonstrated when cortisol fell below $5 \mu \mathrm{g} / \mathrm{dl}(138 \mathrm{nmol} / \mathrm{l})$ the morning following dexamethasone administration (2). The upper normal limit of midnight cortisol concentration was set at $5.4 \mu \mathrm{g} / \mathrm{dl}(149 \mathrm{nmol} / \mathrm{l})$. The cut-off value was the 97th percentile of midnight serum cortisol concentrations in 100 patients with untreated microprolactinoma studied under analogous conditions of stress induced by hospitalization.

Any subject with body mass index (BMI) greater than $30 \mathrm{~kg} / \mathrm{m}^{2}$ was categorized as obese (21). Any subject with systolic blood pressure greater than $140 \mathrm{mmHg}$, or diastolic blood pressure greater than $90 \mathrm{mmHg}$, or on anti-hypertensive treatment was categorized as hypertensive (22). Blood pressure was the average of two seated measurements taken with $5 \mathrm{~min}$ of rest by a physician using standardized techniques. Diabetes mellitus was diagnosed if a subject was on insulin or hypoglycemic agents or when the subject's plasma glucose was greater than $126 \mathrm{mg} / \mathrm{dl}(7.0 \mathrm{mmol} / \mathrm{l})$ at fasting in at least two samples collected on different days (23). Impaired fasting glucose was diagnosed when the subject's plasma glucose was between 110 and $126 \mathrm{mg} / \mathrm{dl}$ $(6.1$ and $7.0 \mathrm{mmol} / \mathrm{l})$ at fasting in at least two samples collected on different days (23). Cardiovascular and cerebrovascular events were ascertained by reviewing retrospectively the patients' history, the discharge summaries and source documents; complementary documentation was requested if necessary. The following definitions were used: (a) myocardial infarction was defined if there was hospitalization in the presence of two or more of the following: typical chest pain, electrocardiographic changes and increased cardiac enzyme concentrations, or by the presence of typical electrocardiogram changes without any previous acute symptomatology (silent myocardial infarction); (b) angina pectoris was diagnosed if there was hospitalization 
and chest pain and documented electrocardiographic signs of coronary ischemia, or if there was a need for coronary revascularization in the absence of acute myocardial infarction (24); (c) stroke was diagnosed if there was hospitalization for a neurologic deficit with symptoms continuing for more than $24 \mathrm{~h}$; (d) transient ischemic attack was defined as a neurologic deficit lasting less than $24 \mathrm{~h}$ (25). Smoking status was defined as active if patients were current or former smokers; sporadic consumption of alcoholic beverages was only reported in some patients.

\section{Statistical analysis}

Database management and all statistical analyses were performed by using the Statistica for Windows software package (Statsoft Inc., Tulsa, OK, USA). Rates and proportions were calculated for categorical data, and means and standard deviations for continuous data; 95\% confidence intervals were always provided. Normality of data was assessed by the KolmogorovSmirnov test. For continuous variables, differences were analyzed by means of the two-tailed Student's t-test when data were normally distributed and by using the Mann-Whitney U test for non-parametric data. Analysis of covariance (ANCOVA) analysis was performed to adjust for possible confounding factors when appropriate. For categorical variables, differences were analyzed by means of the $\chi^{2}$ test and Fisher's exact test when appropriate. Bonferroni adjustment for multiple comparisons was performed when appropriate. Correlation analyses were determined by calculating the Spearman's $r$ coefficient. In addition, multiple regression analysis was performed as appropriate. Missing data were dealt with by excluding patients from particular analyses if their files did not contain data on the required variables. When data are expressed as percent values, these refer to valid cases. Levels of statistical significance were set at $P<0.05$.

\section{Results}

Demographic characteristics were as follows: 135 women and 75 men $(64.3$ vs $36.7 \%, P<0.001)$ aged between 19 and 81 years (median 60 years; means \pm S.D. 58.3 \pm 10.4$)$. Most subjects $(73.3 \%)$ were in their fifties and sixties. The reasons for an abdominal imaging procedure were work-up of known disorders $(34.3 \%)$, aspecific symptoms $(31.9 \%)$, abdominal pain $(24.5 \%)$, including either an ill-defined discomfort, or biliary and renal colic, and other reasons $(9.3 \%)$. In the overall series, the diameter of the adrenal masses estimated by $\mathrm{CT}$ ranged from 0.5 to $6 \mathrm{~cm} \quad(2.6 \pm 1.0 \mathrm{~cm} \quad(95 \%$ confidence interval (C.I.) 2.5-2.7)) and only 15 masses (7.1\%) were larger than $4.0 \mathrm{~cm}$. Masses were more frequent on the right $(51.5 \%)$ than on the left side $(37.4 \%)$, whereas bilateral masses were $11.1 \%$ of the whole series. Hypertension was observed in 113 patients $(53.8 \%)$, obesity in 45 patients $(21.4 \%)$ and hyperglycemia in 47 (22.4\%), 28 of whom had diabetes $(13.3 \%)$ and 19 impaired fasting glucose $(9.1 \%)$.

The endocrine evaluation detected the following alterations in the HPA axis: reduced DHEAS concentrations in 61 patients $(33.1 \%)$, elevated midnight serum cortisol in 47 patients $(29.4 \%)$, cortisol inadequately suppressed by dexamethasone in 23 patients $(13.8 \%)$, increased UFC excretion in 20 patients (10.8\%) and reduced ACTH concentrations in 19 patients $(9.7 \%)$. Overall, the association of at least two alterations of the HPA axis was found in $17.9 \%$ of patients.

Twenty-two patients (18 women and four men aged 39-63 years, median 55.5) underwent adrenalectomy during the study period and the histological diagnosis was adrenal adenoma in all cases. Three to six months after surgery, a significant reduction in midnight cortisol $(2.3 \pm 2.6$ $\mu \mathrm{g} / \mathrm{dl} \quad(63 \pm 72 \mathrm{nmol} / \mathrm{l}) \quad(95 \% \quad$ C.I. $\quad 1.6-3.9 \mu \mathrm{g} / \mathrm{dl}$; $44-108 \mathrm{nmol} / \mathrm{l})$ vs $5.5 \pm 4.9 \mu \mathrm{g} / \mathrm{dl}(152 \pm 135 \mathrm{nmol} / \mathrm{l})$ (95\% C.I. $1.8-9.3 \mu \mathrm{g} / \mathrm{dl} ; 50-257 \mathrm{nmol} / \mathrm{l}), P=0.008)$ and post-dexamethasone cortisol $(1.5 \pm 1.7 \mu \mathrm{g} / \mathrm{dl}$ $(41 \pm 47 \mathrm{nmol} / \mathrm{l}) \quad(95 \% \quad$ C.I. $\quad 1.2-5.9 \mu \mathrm{g} / \mathrm{dl} ; \quad 33-$ $163 \mathrm{nmol} / \mathrm{l})$ vs $4.0 \pm 3.9 \mu \mathrm{g} / \mathrm{dl} \quad(110 \pm 108 \mathrm{nmol} / \mathrm{l})$ (95\% C.I. $2.2-6.8 \mu \mathrm{g} / \mathrm{dl} ; 61-188 \mathrm{nmol} / \mathrm{l}), P=0.009$ ) was observed. UFC did not change significantly (data not shown) while ACTH concentrations, which are expressed as percent values of the lower normal limit, increased significantly after adrenalectomy $(8.7 \pm 5.1 \% \quad(95 \% \quad$ C.I. $\quad 4.5-12.9) \quad$ vs $3.9 \pm 5.5 \%$ (95\% C.I. 1.6-6.1), $\quad P=0.005)$. Systolic blood pressure was significantly lower after adrenalectomy $\quad(125.0 \pm 9.6 \mathrm{mmHg} \quad(95 \%$ C.I. $116.2-133.8)$ vs $\quad 132.7 \pm 13.8 \mathrm{mmHg} \quad(95 \% \quad$ C.I. $123.7-136.8)$, $P=0.04)$ while fasting glucose and BMI did not change significanlty (data not shown).

We looked at possible correlations between endocrine data and the clinical phenotype, stratifying the patients by the presence or not of any of the three most frequent endocrine alterations (failure to adequately suppress to dexamethasone, increase in midnight serum cortisol and reduction in DHEAS concentrations) and comparing the paired groups in terms of demographic, clinical and biochemical variables.

The patients who failed to show a suppression to dexamethasone were 16 women $(69.6 \%)$ and seven men (30.4\%) showing a post-dexamethasone cortisol of $8.5 \pm 3.4 \mu \mathrm{g} / \mathrm{dl}(235 \pm 94 \mathrm{nmol} / \mathrm{l})(95 \%$ C.I. $7.0-10.0 \mu \mathrm{g} / \mathrm{dl}(193-276 \mathrm{nmol} / \mathrm{l}))$. They did not differ in any clinical variable from the patients who showed adequate suppression, with the notable exception of mass size (Table 1). A positive correlation was indeed found between post-dexamethasone cortisol concentration and mass size $(r=0.22, P=0.004)$.

The patients with elevated midnight cortisol were 27 women (57.4\%) and 20 men (42.6\%) showing 
Table 1 Comparison of patients who showed suppression (group A) and those who did not show suppression (group B) to dexamethasone. The number of valid cases for any variable is indicated. Values are means \pm S.D.

\begin{tabular}{|c|c|c|c|c|c|}
\hline & Group A $(n=144)$ & Group B $(n=23)$ & $\boldsymbol{P}$ & $\%$ valid $\mathbf{A}$ & $\%$ valid $B$ \\
\hline Age (years) & $58.4 \pm 10.3(56.7-60.1)$ & $59.8 \pm 12.8(54.2-65.3)$ & NS & 100.0 & 100.0 \\
\hline BMI $\left(\mathrm{kg} / \mathrm{m}^{2}\right)$ & $26.5 \pm 5.1(25.7-27.4)$ & $25.2 \pm 4.3(23.3-27.1)$ & NS & 100.0 & 100.0 \\
\hline Mass size (cm) & $2.5 \pm 1.0(2.3-2.7)$ & $3.0 \pm 1.1(2.5-3.5)$ & 0.04 & 100.0 & 100.0 \\
\hline Fasting glucose (mg/dl) & $108.2 \pm 39.1(101.4-114.8)$ & $98.4 \pm 26.6(86.3-110.5)$ & NS & 100.0 & 100.0 \\
\hline Hyperglycemia $n,(\%)$ & 37 (26.2) & $3(13.5)$ & NS & 100.0 & 100.0 \\
\hline Total cholesterol (mg/dl) & $220.1 \pm 49.3(210.9-229.3)$ & $205.4 \pm 47.6(180.0-230.8)$ & NS & 78.5 & 69.5 \\
\hline Systolic pressure (mmHg) & $138.2 \pm 16.3(135.4-141.1)$ & $135.5 \pm 16.0(127.8-143.3)$ & NS & 100.0 & 100.0 \\
\hline Diastolic pressure (mmHg) & $83.8 \pm 8.9(82.3-85.3)$ & $82.4 \pm 7.5(78.8-86.0)$ & NS & 100.0 & 100.0 \\
\hline Hypertension $n,(\%)$ & $77(53.4)$ & $8(34.7)$ & NS & 100.0 & 100.0 \\
\hline Cardiovascular events $n,(\%)$ & $14(9.7)$ & $4(17.3)$ & NS & 100.0 & 100.0 \\
\hline Smoking $n,(\%)$ & $56(38.9)$ & $8(34.8)$ & NS & 70.1 & 69.6 \\
\hline Family history of hypertension $n,(\%)$ & $62(43.0)$ & $12(52.2)$ & NS & 72.9 & 73.9 \\
\hline Family history of diabetes $n,(\%)$ & $57(39.6)$ & $7(30.4)$ & NS & 75.0 & 82.6 \\
\hline
\end{tabular}

NS, not significiant.

midnight cortisol concentrations of $9.2 \pm 3.3 \mu \mathrm{g} / \mathrm{dl}$ $(254 \pm 91 \mathrm{nmol} / \mathrm{l}) \quad(95 \%$ C.I. $8.0-10.4 \mu \mathrm{g} / \mathrm{dl} \quad(221-$ $287 \mathrm{nmol} / \mathrm{l})$ ). They were older and displayed greater fasting glucose and systolic blood pressure levels than the patients with normal midnight cortisol concentrations (Table 2). The frequency of hypertension and hyperglycemia was found to be increased in the patients with elevated midnight cortisol (Table 2). Since age was significantly correlated with fasting glucose $(r=0.25$, $P=0.0003)$ and systolic blood pressure $(r=0.36$, $P<0.0001)$ respectively, it was used as a covariate in the comparison of these two variables; only the difference in systolic blood pressure remained statistically significant $(P=0.009)$. To control for the interaction of age on systolic blood pressure, we also divided the sample into two groups on the basis of patient age, using the median level of the whole series (60 years) as the cut-off. Regardless of age, the patients with elevated midnight cortisol showed significantly higher systolic blood pressure than the remainder (age $<60$ years, $\quad 146.0 \pm 16.5 \mathrm{mmHg} \quad(95 \% \quad$ C.I. $134.2-157.8 \mathrm{mmHg})$ vs $133.1 \pm 16.4 \mathrm{mmHg} \quad(95 \%$ C.I. $127.7-138.6 \mathrm{mmHg}), P=0.03$; age $>60$ years, $149.6 \pm 15.3 \mathrm{mmHg}$ (95\% C.I. $143.0-156.1 \mathrm{mmHg})$ vs $\quad 140.3 \pm 13.9 \mathrm{mmHg} \quad(95 \% \quad$ C.I. $134.9-$ $145.7 \mathrm{mmHg}), P=0.03)$.

To control for the confounding effect of current antihypertensive treatment, we compared the two groups of patients (with elevated or normal midnight cortisol) after excluding hypertensive patients on treatment: systolic blood pressure remained significantly higher in the patients with elevated midnight cortisol than in the remainder $\quad(142.7 \pm 13.5 \mathrm{mmHg} \quad(95 \%$ C.I. $133.7-$ $151.8 \mathrm{mmHg}) \quad$ vs $\quad 128.5 \pm 12.1 \mathrm{mmHg} \quad(95 \% \quad$ C.I. 124.5-132.6 mmHg), $P=0.001$ after correction for age). The percentage of hypertensive patients undergoing treatment was not different between the two groups (90.5 and $97.1 \%$ respectively) but the percentage of hypertensive patients with blood pressure $<140 / 90 \mathrm{mmHg}$ was significantly lower among the

Table 2 Comparison of patients with normal (group A) or elevated (group B) midnight serum cortisol concentrations. The number of valid cases for any variable is indicated. Values are means \pm S.D.

\begin{tabular}{lccrrr}
\hline & Group A $(n=113)$ & Group B $(n=47)$ & $P$ & $\%$ valid A $\%$ valid B \\
\hline Age (years) & $56.7 \pm 12.1(53.8-59.6)$ & $63.2 \pm 10.8(59.1-67.2)$ & 0.01 & 100.0 & 100.0 \\
BMI (kg/m $\left.{ }^{2}\right)$ & $26.0 \pm 4.5(24.9-27.1)$ & $26.9 \pm 6.4(24.4-29.3)$ & NS & 100.0 & 100.0 \\
Mass size $(\mathrm{cm})$ & $2.5 \pm 0.9(2.3-2.7)$ & $2.7 \pm 1.2(2.2-3.2)$ & NS & 100.0 & 100.0 \\
Fasting glucose $(\mathrm{mg} / \mathrm{dl})$ & $105.1 \pm 39.2(95.6-114.6)$ & $120.4 \pm 52.2(100.2-140.7)$ & 0.04 & 100.0 & 100.0 \\
Hyperglycemia $n,(\%)$ & $20(42.5)$ & 0.009 & 100.0 & 100.0 \\
Total cholesterol $(\mathrm{mg} / \mathrm{dl})$ & $(22.1)$ & $212.5 \pm 42.5(193.6-231.4)$ & $\mathrm{NS}$ & 85.0 & 70.2 \\
Triglycerides $(\mathrm{mg} / \mathrm{dl})$ & $134.7 \pm 98.2(109.6-159.9)$ & $165.3 \pm 103.9(119.2-211.4)$ & $\mathrm{NS}$ & 87.6 & 74.5 \\
Systolic pressure $(\mathrm{mmHg})$ & $136.4 \pm 16.2(132.6-140.3)$ & $148.3 \pm 14.6(142.9-153.8)$ & 0.0009 & 100.0 & 100.0 \\
Diastolic pressure $(\mathrm{mmHg})$ & $83.2 \pm 8.9(81.1-85.3)$ & $85.3 \pm 8.1(82.3-88.3)$ & $\mathrm{NS}$ & 100.0 & 100.0 \\
Hypertension $n,(\%)$ & $56(49.5)$ & $33(70.2)$ & 0.02 & 100.0 & 100.0 \\
Cardiovascular events $n,(\%)$ & $13(11.5)$ & $17(17.0)$ & $\mathrm{NS}$ & 100.0 & 100.0 \\
Smoking $n,(\%)$ & $44(38.9)$ & $26(55.3)$ & $\mathrm{NS}$ & 65.5 & 70.2 \\
Family history of hypertension $n,(\%)$ & $57(50.4)$ & $14(29.8)$ & $\mathrm{NS}$ & 63.1 & 74.5 \\
Family history of diabetes $n,(\%)$ & $37(32.7)$ & & 80.8 \\
\hline
\end{tabular}

NS, not significiant. 
hypercortisolemic patients (12.5 vs $32.4 \%, P=0.04$ ). Glycated haemoglobin (HbA1c) levels were significantly higher in diabetic patients with elevated midnight cortisol levels than in those with normal cortisol levels $(8.9 \pm 1.1 \%$ (95\% C.I. $7.7-10.1 \%)$ vs $7.1 \pm 1.3 \%(95 \%$ C.I. $6.0-8.1 \%), P=0.005$ after correction for age), even if the proportion of patients receiving hypoglycemic agents or insulin was evenly distributed between the two groups (66.7 and $56.2 \%$ respectively).

The patients with reduced DHEAS concentrations were 11 men (18\%) and 50 women (82\%); they did not differ in any clinical variable from the patients who had normal DHEAS concentrations (data not shown).

In the whole series, systolic blood pressure was associated with age $(\beta=0.36, P=0.0001)$ and midnight cortisol concentration $(\beta=0.26, P=0.005)$ in a multiple regression model. The model accounted for $22 \%\left(r^{2}\right)$ of the total variation $(P<0.0001)$. No correlation between age and midnight cortisol was observed. The candidate predictive variables were age, BMI and midnight cortisol concentration. Age and BMI were tested because of the well-known effect of these variables on systolic blood pressure in the general population (22) while midnight cortisol was chosen because it is considered to be the most sensitive index of hypercortisolism $(26,27)$. No statistically significant model was found for diastolic blood pressure.

\section{Discussion}

The outcome of the present study confirmed the demographic data obtained in a previous survey on adrenal incidentaloma in Italy which covered the period between 1980 and 1995 (9): the frequency of detection peaks in the fifth and sixth decades and women outnumber men. This pattern may be due to increased referral for diagnostic procedures or it could be explained by greater occurrence of cortical nodules with age, as observed in unselected autopsy series (4, 5). Autopsy studies did not show any gender difference in the prevalence of adrenal incidentalomas $(4,5)$ while most patients with incidental adrenal masses are women $(2,9,28)$. This may reflect the gender distribution of the population undergoing imaging procedures $(2,28)$.

Several data from autopsy series $(1,2,4)$, cross-sectional studies $(9,16,29)$ and case-control studies (19, 30) consistently point to an association between clinically inapparent adrenal adenoma and some manifestations of the metabolic syndrome (arterial hypertension, hyperglycemia, overweight). The present findings confirmed this association since the frequency of hypertension was remarkably high among our patients, with a rate of $53.8 \%$. The prevalence of hypertension in Italy was found to be about $38 \%$ in a survey of a representative population sample of over 8000 subjects of 35-74 years with an average BMI of 26.4 (it was 26.5 in our patients) (31). The prevalence was higher in men $(44.8 \%)$ than in women $(30.6 \%)$, and this gender-related difference makes more relevant the gap between the general population and the present series, since about two-thirds of our patients were women.

The frequency of hyperglycemia in our patients was $22.4 \%$, including impaired fasting glucose (IFG), 9.1\% and diabetes, $13.3 \%$. The overall prevalence of diabetes in northern Italy was found to range from 2 to $3.3 \%$ in different population-based studies $(32-35)$. The prevalence of known diabetes is negligible until the age of 30 years, when it increases strikingly to a plateau of approximately $10 \%$ in the age groups over 65 years $(34,35)$. The prevalence of IFG is not well characterized in Italy, the only study available reported a figure of $3.2 \%$ in 1245 subjects aged 40-59 years (36). The frequency of obesity was $21.4 \%$ in our patients while it was reported to be $9 \%$ in the general Italian population $(37,38)$. These results support the view that clinically inapparent adrenal adenomas may be associated with an increased risk of metabolic and cardiovascular diseases (18). However, we acknowledge that this assumption must be considered cautiously since this was not a population-based study and referral bias is an obvious issue when dealing with adrenal masses that are discovered in the course of diagnostic work-up of various illnesses or complaints.

In the present series, elevation of midnight serum cortisol concentration was a very frequent alteration of the HPA axis, being observed in $29.4 \%$ of our patients. This is biologically plausible since a high late-night cortisol level appears to be the earliest and most sensitive marker for Cushing's syndrome and so it has been exploited as a diagnostic tool $(26,27)$. The normative range for midnight serum cortisol concentration was generated in a large group of hospitalized patients who did not have evidence of impaired function of the HPA axis (27). Our cut-off value was remarkably higher than that of $1.8 \mu \mathrm{g} / \mathrm{dl}(50 \mathrm{nmol} / \mathrm{l})$ recorded in sleeping normal volunteers studied in a research setting (39); thus, we think that it is sufficiently robust to match the spurious elevation induced by hospitalization stress. Interestingly, patients with midnight serum cortisol higher than $5.4 \mu \mathrm{g} / \mathrm{dl}$ (149 nmol/l) display hypertension, hyperglycemia and history of cardiovascular or cerebrovascular events more frequently than patients with midnight cortisol below that threshold.

Even if the patients with elevated midnight cortisol are older than the patients with normal midnight cortisol, we think that several lines of evidence suggest that the age difference does not fully account for their more adverse cardiovascular risk profile. First, elevated blood pressure in the group of hypercortisolemic patients was confirmed when age was studied as a covariate. Secondly, we performed separate comparisons for age groups below and above the median age value 
of the whole series and we found that the hypercortisolemic patients had higher systolic pressure regardless of age. Thirdly, midnight serum cortisol is a predictor of systolic blood pressure along with age in a multiple regression model, and systolic levels reduced in parallel with midnight cortisol in patients who underwent adrenalectomy. Although we have disclosed the potential presence of confounding factors, the comparison of the two groups of patients with normal or elevated midnight cortisol levels does not demonstrate any significant difference in other key risk factors, such as smoking habits, lipid levels and family history of hypertension or diabetes. The number of individuals receiving anti-hypertensive drugs was evenly distributed among patients with normal or elevated midnight cortisol; however, the proportion of hypertensive individuals with blood pressure levels less than $140 / 90 \mathrm{mmHg}$ was remarkably lower among the hypercortisolemic patients. Moreover, the elevation of systolic blood pressure was confirmed after excluding patients undergoing treatment and this demonstrated that current anti-hypertensive therapy does not confound the interpretation of our results.

In the present study, the association of elevated midnight cortisol with metabolic alterations was weaker than with hypertension, but did not conflict with previous observations that patients with adrenal incidentaloma present the phenotype of insulin resistance. In those studies, elevation of blood glucose levels was more readily apparent after an oral glucose challenge than in a fasting state $(19,30,40,41)$. The observation that our patients with elevated midnight cortisol had a worse control of diabetes may be pertinent to that hypothesis.

Previous studies have reported an increase in the nadir cortisol levels in elderly subjects $(42,43)$. However, it is unlikely that the elevation of midnight cortisol observed in our series may simply reflect premature aging, since no correlation was found between midnight cortisol and age. Further, patients with elevated midnight cortisol were only 7 years older, on average, than patients with normal midnight cortisol, while the age difference between young and elderly subjects was in the range of 30-40 years in the studies reporting an age-associated cortisol increase $(42,43)$.

The issue of reverse causality should also be addressed since a number of cross-sectional cohort studies have found that elevated morning plasma cortisol and/or increased total 24-h urinary cortisol metabolite excretion is associated with insulin resistance, high blood pressure, hyperlipidemia and hyperglycemia, particularly in patients with low birth weight (44-46). More recent studies, however, have not confirmed that cortisol secretion is elevated in patients with established cardiovascular risk factors that cluster in the metabolic syndrome; rather, increased glucocorticoid sensitivity has been increasingly demonstrated, so that the maintenance of normal circulating cortisol concentrations in patients with cardiovascular risk factors may be paradoxical and inappropriate $(47,48)$. By evaluating the daily cortisol profile, a blunted circadian rhythm of cortisol has been found in men with visceral obesity and a cluster of metabolic risk factors (49). The cortisol pattern, however, was characterized by a low morning value rather than an elevated late-evening concentration, as was observed in the present series. Therefore, we have observed a quite different type of dysregulation in the circadian programming of cortisol secretion compared with previous studies which looked at the activity of the HPA axis in the metabolic syndrome. Further, the altered cortisol pattern was reversible after removal of the adrenal adenoma, at least in a subset of patients who were operated on during the study period. In parallel, systolic blood pressure reduced after adrenalectomy. These findings strengthen the concept of relative cortisol excess sustained by an adrenal adenoma in our patients.

The $1 \mathrm{mg}$ dexamethasone suppression test has been extensively employed to detect subclinical hypercortisolism in patients with adrenal incidentaloma (13) and it has been recommended at the recent National Institutes of Health consensus conference as the screening test with the classic threshold of $5 \mu \mathrm{g} / \mathrm{dl}(138 \mathrm{nmol} / \mathrm{l})$ (2). In our series, $13.8 \%$ of patients failed to suppress cortisol below that threshold but such patients did not differ in any clinical variable from the remainder, with the only exception of bearing larger masses, as was previously reported (29). Increase in UFC excretion is less frequently found and this confirms the view that measurement of UFC has insufficient sensitivity to detect mild hypercortisolism (50). It has been previously reported that a blunted circadian rhythm of cortisol may frequently occur in patients with adrenal incidentaloma despite the fact that UFC is infrequently elevated $(15-17,51)$. Even less frequent is the observation of undetectable ACTH concentrations, raising the possibility that the degree of cortisol excess may be only rarely sufficient to suppress pituitary ACTH secretion; technical reasons concerning the assay methodology may partially underlie this result (50). Conversely, reduction in DHEAS concentration is very common, thus confirming previous research, but it remains uncertain whether this finding reflects blunted ACTH secretion and may be viewed as an indirect marker of autonomous cortisol secretion (51, 52). None of these endocrine alterations is associated with any clinical phenotype in our series.

To summarize, the present data raised in a large multi-institutional database suggested that elevated midnight cortisol concentration is a valuable clue to select a subgroup of patients with clinically inapparent adrenal adenoma at higher risk of cardiovascular and metabolic diseases. The association of midnight cortisol with systolic blood pressure is particularly relevant in this context since outcome trials in hypertension have demonstrated that isolated systolic 
hypertension is a predictor of major cardiovascular events and total mortality in the elderly $(53,54)$. An average difference of $12 \mathrm{mmHg}$ in systolic blood pressure between patients with elevated or normal midnight cortisol may be clinically relevant. In a recently published meta-analysis of more than 40 randomized controlled trials of blood pressure reduction, each $10 \mathrm{mmHg}$ lower systolic blood pressure was associated with a decrease in risk of stroke of approximately onethird in subjects aged 60 to 79 years (55). Since many uncertainties and controversies remain about the definition of subclinical Cushing's syndrome (2, 10-14), the demonstration that a single hormonal parameter may be associated with patient outcome is tantalizing and could be of practical importance. However, there are several limitations of our study including its retrospective nature, incomplete data reporting in a subset of patients and lack of central hormone measurement. Prospective studies are needed to confirm that measurement of midnight serum cortisol, or possibly salivary cortisol $(56,57)$, may become a more reliable test to detect clinically relevant subclinical hypercortisolism.

\section{Acknowledgements}

This work was partially supported by the Ministero dell'Università e della Ricerca Scientifica e Tecnologica (grant no. 2001062719_004).

\section{References}

1 Kloos RT, Gross MD, Francis IR, Korobkin M \& Shapiro B. Incidentally discovered adrenal masses. Endocrine Reviews 199516 $460-484$.

2 Grumbach MM, Biller BMK, Braunstein GD, Campbell KK, Carney JA, Godley PA, Harris EL, Lee JKT, Oertel YC, Posner MC, Schlechte JA \& Wieand HS. Management of the clinically inapparent adrenal mass ('incidentaloma'). Annals of Internal Medicine $2003138424-429$.

3 Mansmann G, Lau J, Balk E, Rothberg M, Miyachi Y \& Bornstein SR. The clinically inapparent adrenal mass: update in diagnosis and management. Endocrine Reviews 200425 309-340.

4 Russi S, Blumenthal HT \& Gray SH. Small adenomas of the adrenal cortex in hypertension and diabetes. Archives of Internal Medicine 194576 284-291.

5 Commons RR \& Callaway CP. Adenomas of the adrenal cortex. Archives of Internal Medicine $1948 \mathbf{8 1} 37-41$.

6 Cook DM \& Loriaux DL. The incidental adrenal mass. American Journal of Medicine $1996 \mathbf{1 0 1} 88-94$.

7 Chidiac RM \& Aron DC. Incidentalomas. A disease of modern technology. Endocrinology and Metabolism Clinics of North America $199726233-253$.

8 Copeland PM. Adrenal incidentaloma. Current Trends in Endocrinology and Metabolism $19976189-194$.

9 Mantero F, Terzolo M, Arnaldi G, Osella G, Masini AM, Alì A, Giovanetti M, Opocher G \& Angeli A. A survey on adrenal incidentaloma in Italy. Journal of Clinical Endocrinology and Metabolism $200085637-644$
10 Young WF. Management approaches to adrenal incidentalomas: a view from Rochester, Minnesota. Endocrine and Metabolism Clinics of North America 200029 159-185.

11 Terzolo M, Osella G, Alì A \& Angeli A. Adrenal incidentalomas. In Functional and Morphological Imaging of the Endocrine System. Endocrine Updates, pp 191-211. Ed. WW De Herder. Boston: Kluwer Academic Publishers vol 7, 2000.

12 Kievit J \& Haak HR. Diagnosis and treatment of adrenal incidentaloma: a cost effectiveness analysis. Endocrinology and Metabolism Clinics of North America 200029 69-88.

13 Reincke M. Subclinical Cushing's syndrome. Endocrinology and Metabolism Clinics of North America 200029 42-56.

14 Ross NS. Epidemiology of Cushing's syndrome and subclinical disease. Endocrinology and Metabolism Clinics of North America 1994 23 539-546.

15 Reincke M, Nieke J, Krestin GP, Saeger W, Allolio B \& Winkelman W. Preclinical Cushing's syndrome in adrenal 'incidentalomas': comparison with adrenal Cushing's syndrome. Journal of Clinical Endocrinology and Metabolism 199275 826-832.

16 Ambrosi B, Peverelli S, Passini E, Re T, Ferrario R, Colombo P, Sartorio A \& Faglia G. Abnormalities of endocrine function in patients with clinically 'silent' adrenal masses. European Journal of Endocrinology 1995132 422-428.

17 Terzolo M, Alì A, Osella G, Cesario F, Paccotti P \& Angeli A. Subclinical Cushing's syndrome in adrenal incidentaloma. Clinical Endocrinology $1998 \mathbf{4 8} 89-97$.

18 Angeli A \& Terzolo M. Editorial: Adrenal incidentaloma - a modern disease with old complications (Editorial comment). Journal of Clinical Endocrinology and Metabolism $2002 \quad 87$ $4869-4871$.

19 Terzolo M, Pia A, Alì A, Osella G, Reimondo G, Bovio S, Daffara F, Procopio M, Paccotti P, Borretta G \& Angeli A. Adrenal incidentaloma: a new cause of the metabolic syndrome? Journal of Clinical Endocrinology and Metabolism 200287 998-1003.

20 Arlt W \& Allolio B. Adrenal insufficiency. Lancet 2003361 1881-1893.

21 Bray GA. An approach to the classification and evaluation of obesity. In Obesity, pp 294-308. Eds P Björntorp \& BN Brodoff. Philadelphia: Lippincott, 1992.

22 Guidelines Committee European Society of Hypertension European Society of Cardiology guidelines for the management of arterial hypertension. Journal of Hypertension 200321 10111053.

23 The Expert Committee on the Diagnosis and Classification of Diabetes Mellitus. Report of the Expert Committee on the Diagnosis and Classification of Diabetes Mellitus. Diabetes Care 199720 $1183-1197$

24 The Joint European Society of Cardiology/American College of Cardiology Committee. Myocardial infarction redefined - a consensus document of the Joint European Society of Cardiology Committee for the redefinition of myocardial infarction. Journal of American College of Cardiology 200036 959-969

25 Hack W, Kaste M, Bogousslavsky J. Brainin M, Chamorro A, Lees K, Leys D, Kwiecinski H, Toni P, Langhorne P, Diener C, Hennerici M, Ferro J, Sivenius J, Gunnar N, Olsen TS \& Gugging M. European Stroke Initiative Executive Committee and the EUSI Writing Committee. European Stroke Initiative Recommendations for Stroke Management - update 2003. Cerebrovascular Diseases 200316 311-337.

26 Papanicolaou DA, Yanovski JA, Cutler GB, Chrousos GP \& Nieman LK. A single midnight cortisol measurement distinguishes Cushing's syndrome from pseudo-Cushing states. Journal of Clinical Endocrinology and Metabolism $1998 \quad 83$ 1163-1167.

27 Raff H \& Findling JW. A physiologic approach to diagnosis of the Cushing syndrome. Annals of Internal Medicine $2003 \mathbf{1 3 8}$ 980-991.

28 Barzon L, Sonino N, Fallo F, Palù G \& Boscaro M. Prevalence and natural history of adrenal incidentalomas. European Journal of Endocrinology 2003149 273-285. 
29 Barzon L, Scaroni C, Sonino N, Fallo F, Gregianin M, Macrì C \& Boscaro M. Incidentally discovered adrenal tumors: endocrine and scintigraphic correlates. Journal of Clinical Endocrinology and Metabolism $1988 \mathbf{8 3} 55-62$.

30 Tauchmanova L, Rossi R, Biondi B, Pulcrano M, Nuzzo V, Palmieri E-A, Fazio S \& Lombardi G. Patients with subclinical Cushing's syndrome due to adrenal adenoma have increased cardiovascular risk. Journal of Clinical Endocrinology and Metabolism $2002874872-4878$.

31 Wolf-Maier K, Cooper RS, Banegas JR, Giampaoli S, Hense H-W, Joffres M, Kastarinen M, Poulter N, Primatesta P, RodriguezArtalejo F, Stegmayr B, Thamm M, Tuomilehto J, Vanuzzo D \& Vescio F. Hypertension prevalence and blood pressure levels in 6 European Countries, Canada, and the United States. Journal of the American Medical Association 2003289 2363-2369.

32 Bruno G, Bargero G, Vuolo A, Pisu E \& Pagano G. A populationbased prevalence survey of known diabetes mellitus in northern Italy based upon multiple independent sources of ascertainment. Diabetologia $199235851-856$.

33 Di Cianni G, Benzi L, Giannarelli R, Orsinii P, Villan G, Ciccarone AM, Cecchetti P, Fedele $O$ \& Navalesi R. A prevalence study of known diabetes mellitus in Tuscany assessed from pharmaceutical prescriptions and other independent sources. Acta Diabetologia $19943187-90$.

34 Muggeo M, Verlato G, Bonora E, Ciani F, Moghetti P, Eastman R, Crepaldi G \& de Marco R. Long-term instability of fasting plasma glucose predicts mortality in elderly NIDDM patients: the Verona Diabetes Study. Acta Diabetologia 199538 672-679.

35 Garancini MP, Sergi A, Lazzari P \& Gallus G. Epidemiology of known diabetes in Lombardy, North Italy. Clinical characteristics and methodological aspects. Acta Diabetologia 199532 268-272.

36 Vaccaro O, Ruffa G \& Riccardi G. Is there any use for the oral glucose tolerance test? Diabetes Care 200023 714-715.

37 Pagano G \& La Vecchia C. Overweight and obesity in Italy, 19901991. International Journal of Obesity and Related Metabolic Disorders $199418665-669$.

38 Istituto Auxologico Italiano. II Rapporto sull Obesità in Italia, F Angeli.Milan, 2000, pp 13-18.

39 Newell-Price J, Trainer P, Perry L, Wass J, Grossman A \& Besser M. A single sleeping midnight cortisol has $100 \%$ sensitivity for the diagnosis of Cushing's syndrome. Clinical Endocrinology 1995 $43545-550$.

40 Fernandez-Real JM, Ricart EW, Simò R, Salinas I \& Webb SM. Study of glucose tolerance in consecutive patients harbouring incidental adrenal tumours. Clinical Endocrinology $1998 \mathbf{4 9}$ 53-61.

41 Garrapa GGM, Pantanetti P, Arnaldi G, Mantero F \& Faloia E. Body composition and metabolic features in women with adrenal incidentaloma or Cushing's syndrome. Journal of Clinical Endocrinology and Metabolism $2001865301-5306$.

42 Deuschle M, Gotthardt U, Schweiger U, Weber B, Kdrner A, Schmider J, Standhardt H, Lammers C-H \& Heuser I. With aging in humans the activity of the hypothalamus-pituitary-adrenal system increases and its diurnal amplitude flattens. Life Science $1997612239-2246$.

43 Raff H, Raff JL, Duthie EH, Wilson CR, Sasse EA, Rudman I \& Mattson D. Elevated salivary cortisol in the evening in healthy elderly men and women: correlation with bone mineral density. Journal of Gerontology Series A, Biological Sciences Medical Sciences 199954 M479-M483.

44 Phillips DIW, Barker DJP, Fall CHD, Whorwood CB, Seckl JR, Wood PJ \& Walker BR. Elevated plasma cortisol concentrations: an explanation for the relationship between low birthweight and adult cardiovascular risk factors. Journal of Clinical Endocrinology and Metabolism $1998 \mathbf{8 3} 757-760$.

45 Walker BR, Phillips DIW, Noon JP, Panarelli M, Best R, Edwards HE, Holton DW, Seckl JR, Webb DJ \& Watt GCM. Increased glucocorticoid activity in men with cardiovascular risk factors. Hypertension $199831891-895$.

46 Reynolds RM, Walker BR, Phillips DIW, Sydall HE, Andrew R, Wood PJ \& Whorwood CB. Altered control of cortisol secretion in adult men with low birthweight and cardiovascular risk factors. Journal of Clinical Endocrinology and Metabolism $200186245-250$.

47 Rask E, Olsson T, Soderberg S, Andrew R, Livingstone DEW, Johnson $\mathrm{O} \&$ Walker BR. Tissue-specific dysregulation of cortisol metabolism in human obesity. Journal of Clinical Endocrinology and Metabolism 200186 1418-1421.

48 Andrews RC, Herlihy O, Livingstone DEW, Andrew R \& Walker BR. Abnormal cortisol metabolism and tissue sensitivity to cortisol in patients with glucose intolerance. Journal of Clinical Endocrinology and Metabolism $2002 \mathbf{8 7} 5587-5593$.

49 Rosmond R \& Bjorntorp P. The hypothalamic-pituitary-adrenal axis activity as a predictor of cardiovascular disease, type 2 diabetes and stroke. Journal of Internal Medicine 2000247 188-197.

50 Arnaldi G, Angeli A, Atkinson AB, Bertagna X, Cavagnini F, Chrousos GP, Fava GA, Findling JW, Gaillard RC, Grossman AB, Kola B, Lacroix A, Mancini T, Mantero F, Newell-price J, Nieman LK, Sonino N, Vance ML, Giustina A \& Boscaro M. Diagnosis and complications of Cushing's syndrome: a consensus statement. Journal of Clinical Endocrinology and Metabolism 2003 88 5593-5602.

51 Osella G, Terzolo M, Borretta G, Magro G, Alì A, Piovesan A, Paccotti P \& Angeli A. Endocrine evaluation of incidentally discovered adrenal masses (incidentalomas). Journal of Clinical Endocrinology and Metabolism $1994791532-1539$.

52 Tsagarakis S, Roboti C, Kokkoris P, Vasiliou V, Alevizaki C \& Thalassinon N. Elevated post-dexamethasone suppression cortisol concentrations correlate with hormonal alterations of the hypothalamo-pituitary-adrenal axis in patients with adrenal incidentalomas. Clinical Endocrinology 199849 165-171.

53 Staessen JA, Gasowski J, Wang JG, Thijs L, Den Hond E, Boissel J-P, Coope J, Ekbom T, Gueyffier F, Liu L, Kerlikowske K, Pocock S \& Fagard RH. Risks of untreated and treated isolated systolic hypertension in the elderly: meta-analysis of outcome trials. Lancet $2000355865-872$.

54 SHEP Collaborative Research Group, Prevention of stroke by antihypertensive drug treatment in older persons with isolated systolic hypertension: final results of the Systolic Hypertension in the Elderly Program (SHEP). Journal of the American Medical Association $19912653255-3264$.

55 Lawes CMM, Bennett DA, Feigin VL \& Rodgers A. Blood pressure and stroke. Stroke 200435 776-785.

56 Papanicolaou DA, Mullen N, Kirou I \& Nieman LK. Nighttime salivary cortisol: a useful test for the diagnosis of Cushing's syndrome. Journal of Clinical Endocrinology and Metabolism 200287 4515-4521.

57 Raff H, Raff JL \& Findling JW. Late-night salivary cortisol as a screening test for Cushing's syndrome. Journal of Clinical Endocrinology and Metabolism $1998 \mathbf{8 3} 2681-2686$.

Received 10 February 2005

Accepted 10 May 2005 